\title{
AEROMAGNETIC MAP OF THE MONTESANO QUADRANGLE GRAYS HARBOR AND PACIFIC COUNTIES, WASHINGTON
}

By

John R. Henderson, Natalie S. Tyson, Ernest F. McGowan and others

GEOPHYSICAL INVESTIGATIONS

MAP GP 178

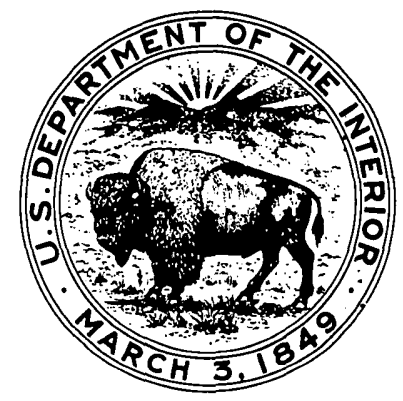

